\title{
Ocular Sarcoidosis as a Presenting Symptom of the
}

\section{Systemic Disease}

\section{Joseph R*and Agemy S}

State University of New York Downstate Medical Center, United States

\section{Image Article}

Volume 2 Issue 1

Received Date: May 02, 2017

Published Date: May 09, 2017

*Corresponding author: Joseph J Raevis, MD, State University of New York Downstate Medical Center, 806 President Street Apartment 2F, Brooklyn NY 11215, United States, Tel: 848-667-3253; E-mail: jjr223@georgetown.edu

\section{Introduction}

A 32-year-old man with no systemic complaints presents with flashers, floaters and blurry vision in the left eye for one week. Fundus examination reveals right eye (Figure 1A) intraretinal hemorrhages (black arrowhead) and perivascular sheathing of retinal veins (black arrow). The left eye (Figure 1B) shows a macular star (white arrowhead) and an elevated inferior granuloma (white arrow) with distal hemorrhages. Testing revealed an elevated angiotensin-converting enzyme (ACE) level, chest X-ray showed bilateral hilar lymphadenopathy (Figure 1C) and OCT imaging of the left macular star revealed hard exudates and subretinal fluid (Figure 1D). Biopsy via bronchoscopy showed granulomatous disease secondary to sarcoidosis.

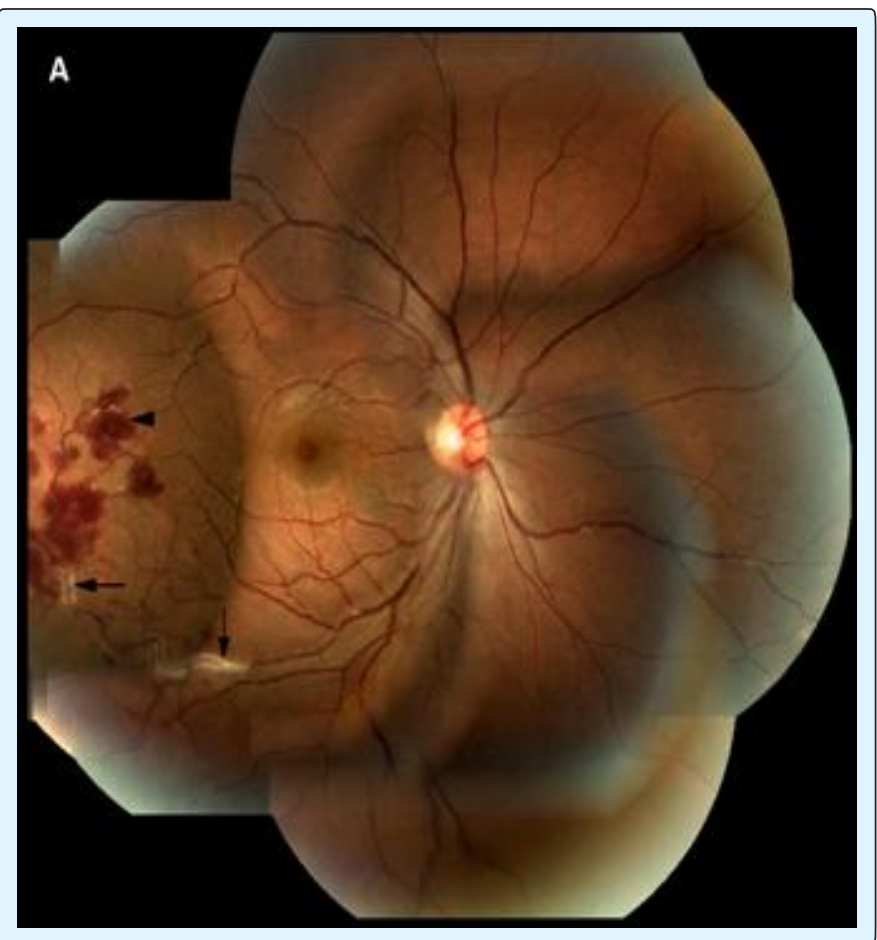

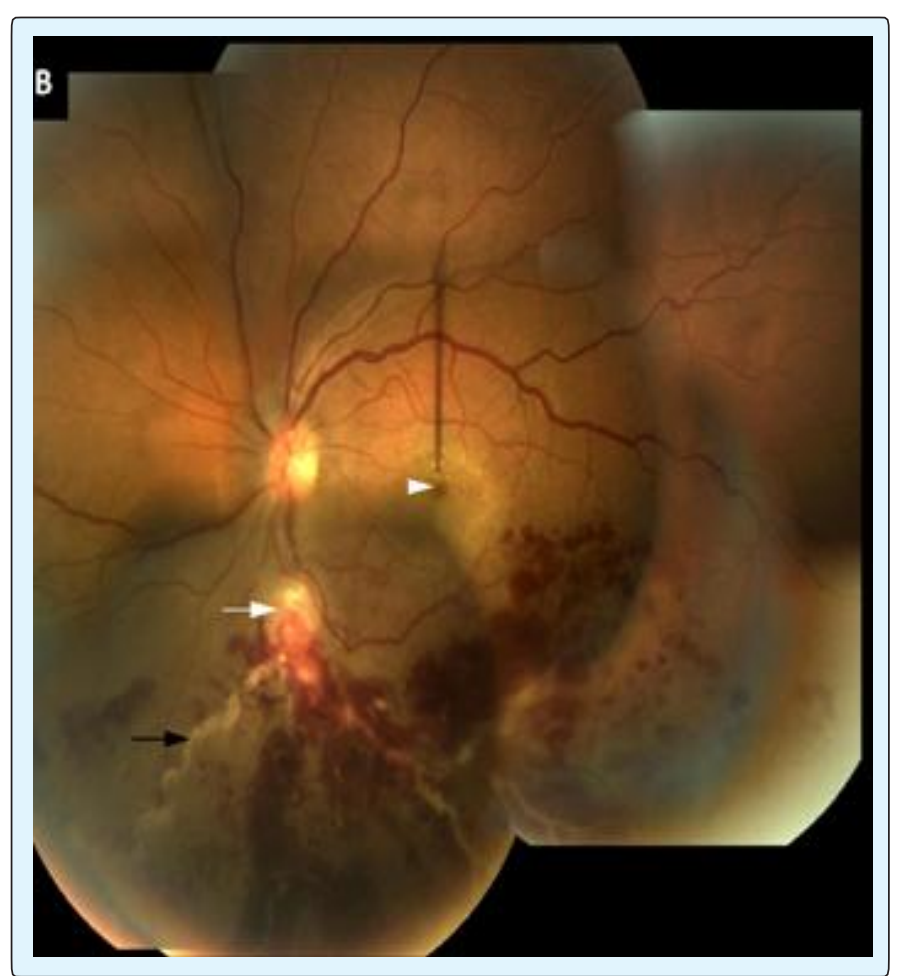

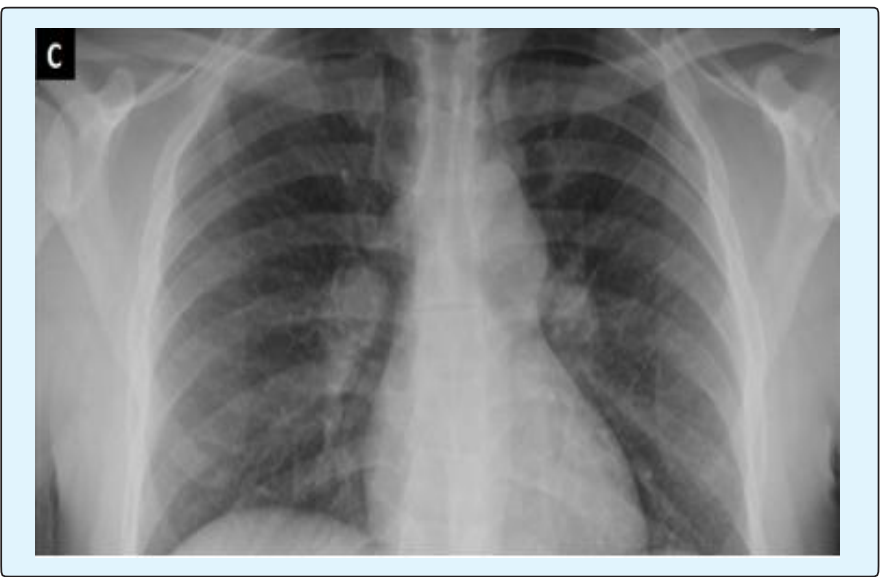




\section{Open Access Journal of Ophthalmology}

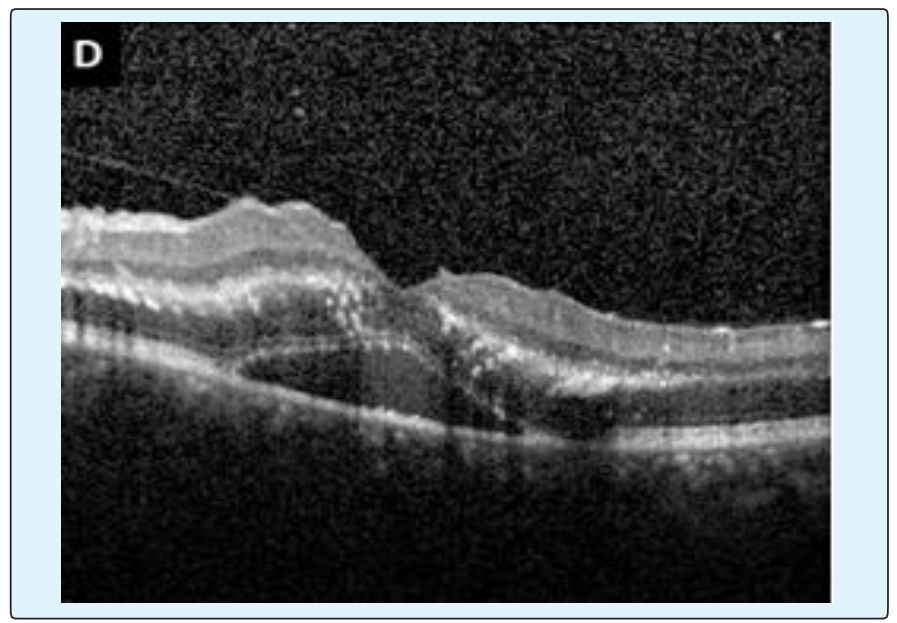

